\title{
Descrição do Comportamento das velocidades máximas mensais do vento utilizando o WRF-ARW
}

Description of the behavior of monthly maximum wind speeds using ARW-WRF

\author{
I. Franco; A. Gutierrez; J. Cataldo \\ Instituto de Mecánica de los Fluídos e Ingeniería Ambiental, Facultad de Ingeniería, Universidad de la República, \\ Uruguay. \\ Ifranco@fing.edu.uy
}

(Recebido em 10 de maio de 2017; aceito em 22 de maio de 2017)

\begin{abstract}
Este artigo tem como objetivo caracterizar de forma mensal as velocidades máximas do vento para alturas acima de dez metros. Considerando a ausência de medições disponíveis para tais alturas, foi utilizado o modelo WRF e uma base de dados CFSR como entrada para o modelo, sendo uma forma alternativa, onde foram realizados um pré- processamento, execuçãoe pós-processamento dos dados simulados para o período compreendido entre os anos 1979 a 2015. Para ajustar os dados de saída do modelo WRF, foram utilizados dados de torres de três diferentes localizações, sendo fornecidos os mesmo pela companhia de energia elétrica UTE, onde de posse dos mesmos foi possível ajustar no pós-processamento os dados históricos de velocidade do vento para as torres consideradas. Com a metodologia descrita é possível gerar dados históricos dos locais que não possuem informações de medições, desenvolvendo neste processo uma ferramenta que pode ser usada por qualquer usuário para gerar informações históricas de grandes períodos a partir dos dados CFSR, usando o modelo WRF e um período recente de dados históricos medidos in situ.

Palavras-chave: WRF, Períodos históricos, ventos severos
\end{abstract}

This paper main objective is to characterize the wind speed monthly maximums for heights over ten meters. Considering the lack of measurements available for such heights, WRF modeling using CFSR historical data base was the alternative considered, preprocessing, running and post processing data for the period between years 1979 and 2015. In order to make a proper adjustment of the data produced by the WRF model, tower data from three different locations provided by the power company UTE was used, generating adjusted post processed wind speed historical data for the towers considered. The methodology described made possible the generation of historical data from places where such information was not available, developing in the process a tool that allow any user to generate long term historical information from CFSR data, by using WRF model and short term historical data.

Keywords. WRF, Return period, severe winds

\section{INTRODUCTION}

Events of severe wind happen and have happened in Uruguayan territory along the history, causing significant physical and economical damage. Such context makes relevant the study of this kind of event in order to understand them and particularly be able to characterize them and their behavior in national territory, seeking the development of useful tools for the prevention of the damage previously mentioned.

Long term and geographically distributed wind speed series are necessary in the assessment of severe wind events. Wind measurements series from anemometric towers are widely used, one example of that is [1], where anemometer measured series are used to produce return period plots. Long enough measured 
series for heights over $10 \mathrm{~m}$ are not available for Uruguayan territory.

The following article pretends to be a first approach to the generation of historical wind speed series using a nonclassical method that involves the generation of data series by numerical modeling and its later adjustment considering the measurements made in anemometric towers. This methodology will generate information of wind speed at heights over ten meters and for a period longer than the available for tower measurement. Following this method, it is possible to generate long enough series that will allow the production of the cumulative distribution function of extreme events, making possible the calculation of design wind speeds.

\section{ARW-WRF MODEL AND DATABASES}

WRF (Weather Research and Forecasting model) [2] is the model used to generate long term wind speed series. Examples of the use of such model for the study of different situations can be found in [3], [4], [5], and [6]. WRF is run with data provided by the CFSR (Climate Forecast System Reanalysis) [7] database, a product of the NCEP (National Center of Environmental Prediction) that provides the data in a grid of $0.5^{\circ}$ every 6 hours for the period conceived from the year 1979 until present. For the runs implemented in this article, the model was configured to calculate hourly mean speed values in a grid of eighteen kilometers.

Moreover, the data used for the comparison was generated by the anemometric tower net owned by UTE, which saves the speed averaged on ten minutes periods since year 2008. The towers used in this article are:

Pampa: Tower situated in $32,247^{\circ} \mathrm{S} 56,215^{\circ} \mathrm{W}$, the region of Tacuarembo (Uruguay). This tower provides data at 72 meters of height for the period 10/7/2008 - 8/31/2015.

Peralta: located close to Pampa, this tower is also in Tacuarembó region. An anemometer installed at 74 meters of height registers the data used, and the exact location of the tower is $32,578^{\circ} \mathrm{S} 56,413^{\circ} \mathrm{W}$. The period of availability of data is $7 / 1 / 2008-8 / 31 / 2015$.

Piedras de Afilar: This tower is located in Canelones region. Its closeness to the capital city Montevideo makes this tower interesting for the study. Tower coordinates are $34,682^{\circ} \mathrm{S}$ $55,575^{\circ} \mathrm{W}$ and the height at which the anemometer used is installed is 64 meters above the ground. The period in which data is available is 7/1/2008 - 8/31/2015.

The different data frequency between the model output and the tower data forces the hourly averaging of the tower data in order to be able to make a correct comparison. Such calculation has been done using the following equation.

$$
\begin{gathered}
v_{\text {hourly }}(n)=\frac{\sum_{i=n-3}^{i=n+2} v_{10 \min }(i)}{6} \\
\text { Equation } 1-\text { Hourly mean wind speed }
\end{gathered}
$$

Where $\mathrm{n}$ is the position in the column of hourly mean wind speed.

Figure 1 shows in a map the location of the three towers. 


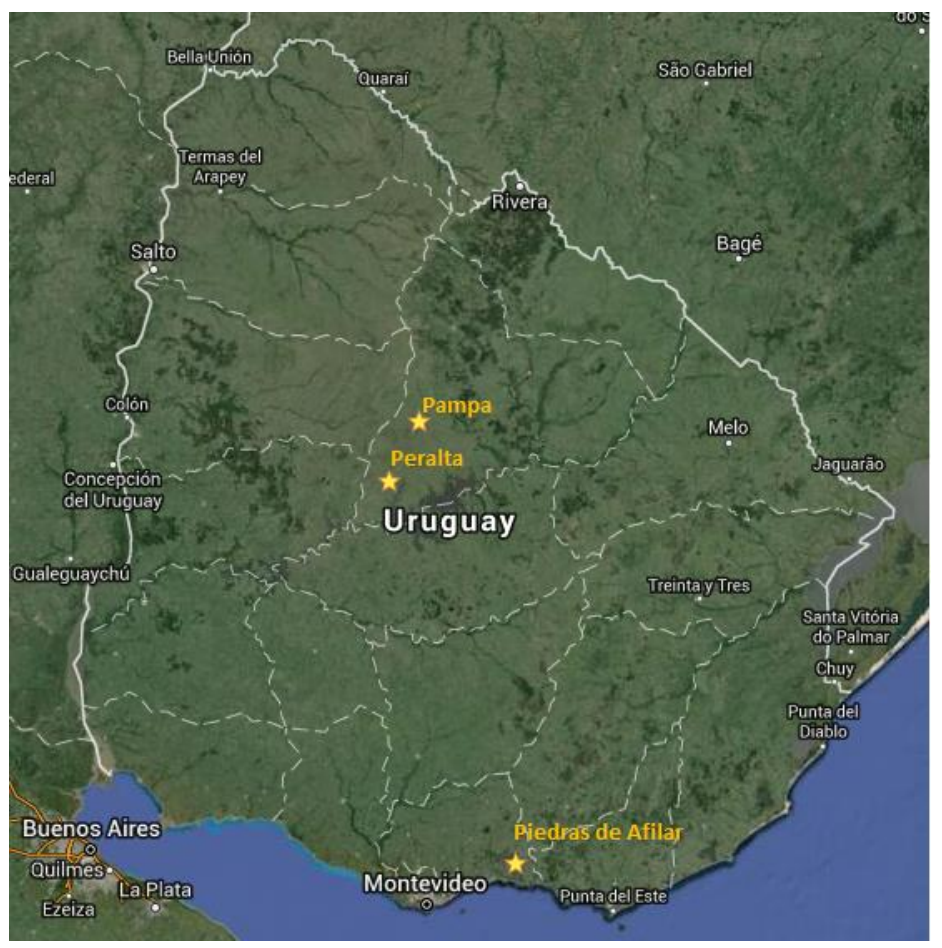

Figure 1 - Location of anemometric towers used.

\section{DATA PROCESSING}

The towers provide information for a period of approximately seven years between July of 2008 and August of 2015. From the comparison for that period of the wind speed simulated and measured, a correct adjustment for the simulation output was possible, making also possible the extension of the trustworthy wind speed data available from the period of tower data availability to the period of CFSR data availability.

\subsection{ETA level selection}

The WRF model output provides wind speed at 41 different vertical levels, identified as ETA. The first step was to determine the levels at which the model output better correlates with the data measured at each tower. In order to be able to adjust the model output to the reality measured at each tower, the series produced were split in two sub series according to the atmospheric thermodynamic stability, considering for the adjustment the comparison between the measurements and the model output for each ETA level and stability state.

The stability states, as described in [8], are related with the heat exchange between the planetary surface and the air, generating a day cycle. Such evolution may lead to a difference between the levels that best describe the wind speed reality at the measured heights, as a cause of a higher or lower interaction between the air vertical layers. The classification of this stability states followed is based on the Richarson number, which results of the comparison between the buoyancy and the inertial force, and which expression is presented below.

$$
R i=\frac{g}{\theta} \cdot\left(\frac{\partial \theta / \partial z}{(\partial U / \partial)^{2}}\right)
$$

Equation 2 - Richardson number 
The sign in the Richardson number indicates the stability state, being unstable if being negative, stable if being positive, and in case of being zero the atmospheric stability state is neutral.

The determination of the stability state was done by comparing the potential temperature modeled by the WRF at ETA levels 2 and 9, and relating the sign of its difference with the sign of the Richardson number.

The correlation coefficient (r) and the Mean Absolute Error (MAE), were the quantities used to compare the series produced by the model for diferent models and the ones masured in the tower. Such quantities are defined as follows:

$$
\begin{gathered}
r_{X Y}=\frac{\sigma_{X Y}}{\sigma_{X} \sigma_{Y}}=\frac{E\left[\left(X-\mu_{X}\right)\left(Y-\mu_{Y}\right)\right]}{\sigma_{X} \sigma_{Y}} \\
\text { Equation 3-Correlation coefficient } \\
\text { MAE }=\frac{1}{n} \sum_{1}^{n}|X(i)-Y(i)| \\
\text { Equation 4 - Mean Absolute Error }
\end{gathered}
$$

Tables 1, 2 and 3 show the values of the quantities used to characterize the comparison for each ETA level the model output and the tower measurements.

Table 1: MAE, $r$ and $b$ for the 20 first $p$ levels of WRF output in Pampa tower

\begin{tabular}{ccccccc}
\hline \multicolumn{7}{c}{ Pampa tower } \\
\hline ETA & MAE & r & b & MAE & r & b \\
\hline 1 & 2.708 & 0.589 & 1.719 & 2.144 & 0.665 & 1.440 \\
2 & 1.849 & 0.569 & 1.283 & 1.783 & 0.676 & 1.247 \\
3 & 1.555 & 0.549 & 1.091 & 1.666 & 0.681 & 1.177 \\
4 & 1.520 & 0.545 & 0.978 & 1.606 & 0.685 & 1.138 \\
5 & 1.601 & 0.550 & 0.903 & 1.564 & 0.689 & 1.106 \\
6 & 1.723 & 0.561 & 0.850 & 1.537 & 0.692 & 1.083 \\
7 & 1.851 & 0.572 & 0.812 & 1.517 & 0.695 & 1.062 \\
8 & 1.942 & 0.582 & 0.789 & 1.500 & 0.698 & 1.047 \\
9 & 2.007 & 0.590 & 0.775 & 1.492 & 0.698 & 1.033 \\
10 & 2.071 & 0.597 & 0.762 & 1.485 & 0.700 & 1.023 \\
11 & 2.130 & 0.602 & 0.752 & 1.481 & 0.701 & 1.012 \\
12 & 2.186 & 0.607 & 0.742 & 1.477 & 0.702 & 1.002 \\
13 & 2.228 & 0.611 & 0.735 & 1.476 & 0.702 & 0.992 \\
14 & 2.499 & 0.630 & 0.698 & 1.490 & 0.702 & 0.944 \\
15 & 3.170 & 0.652 & 0.630 & 1.715 & 0.699 & 0.833 \\
16 & 3.730 & 0.645 & 0.578 & 2.207 & 0.700 & 0.728 \\
17 & 3.424 & 0.571 & 0.595 & 2.385 & 0.671 & 0.708 \\
18 & 3.319 & 0.449 & 0.611 & 2.601 & 0.577 & 0.699 \\
19 & 3.521 & 0.335 & 0.598 & 2.972 & 0.460 & 0.667 \\
20 & 3.910 & 0.245 & 0.560 & 3.442 & 0.362 & 0.616 \\
\hline
\end{tabular}


Table 2: MAE, $r$ and $b$ for the 20 first $p$ levels of WRF output in Peralta tower

\begin{tabular}{ccccccc}
\hline \multicolumn{7}{c}{ Peralta tower } \\
Stable & \multicolumn{3}{c}{ Unstable } \\
\hline ETA & MAE & r & b & MAE & r & b \\
\hline 1 & 4.254 & 0.332 & 2.040 & 2,818 & 0.447 & 1.505 \\
2 & 3.407 & 0.344 & 1.551 & 2,499 & 0.460 & 1.299 \\
3 & 2.990 & 0.353 & 1.331 & 2,385 & 0.468 & 1.225 \\
4 & 2.759 & 0.362 & 1.197 & 2,319 & 0.474 & 1.182 \\
5 & 2.638 & 0.371 & 1.106 & 2,264 & 0.484 & 1.148 \\
6 & 2.584 & 0.377 & 1.038 & 2,228 & 0.489 & 1.122 \\
7 & 2.574 & 0.382 & 0.989 & 2,196 & 0.494 & 1.099 \\
8 & 2.580 & 0.387 & 0.958 & 2,177 & 0.497 & 1.082 \\
9 & 2.592 & 0.390 & 0.939 & 2,160 & 0.500 & 1.068 \\
10 & 2.609 & 0.392 & 0.923 & 2,148 & 0.502 & 1.057 \\
11 & 2.628 & 0.394 & 0.909 & 2,137 & 0.503 & 1.045 \\
12 & 2.648 & 0.396 & 0.896 & 2,131 & 0.504 & 1.035 \\
13 & 2.667 & 0.397 & 0.886 & 2,125 & 0.505 & 1.025 \\
14 & 2.778 & 0.403 & 0.841 & 2,127 & 0.507 & 0.969 \\
15 & 3.112 & 0.414 & 0.766 & 2,283 & 0.507 & 0.864 \\
16 & 3.563 & 0.401 & 0.710 & 2,637 & 0.507 & 0.769 \\
17 & 3.608 & 0.340 & 0.731 & 2,794 & 0.473 & 0.755 \\
18 & 3.701 & 0.268 & 0.753 & 3,001 & 0.397 & 0.752 \\
19 & 3.912 & 0.204 & 0.738 & 3,324 & 0.312 & 0.721 \\
20 & 4.192 & 0.154 & 0.697 & 3,726 & 0.253 & 0.670 \\
\hline
\end{tabular}

Table 3: MAE, $r$ and $b$ for the 20 first ETA levels of WRF output in Piedras de Afilar tower

\begin{tabular}{|c|c|c|c|c|c|c|}
\hline \multicolumn{7}{|c|}{ Piedras de Afilar tower } \\
\hline \multirow[b]{2}{*}{ ETA } & \multicolumn{3}{|c|}{ Stable } & \multicolumn{3}{|c|}{ Unstable } \\
\hline & MAE & $\mathbf{r}$ & $\mathbf{b}$ & MAE & $\mathbf{r}$ & b \\
\hline 1 & 1.828 & 0.608 & 1.061 & 1.741 & 0.772 & 0.844 \\
\hline 2 & 1.815 & 0.600 & 0.933 & 2.001 & 0.774 & 0.795 \\
\hline 3 & 1.934 & 0.594 & 0.871 & 2.119 & 0.775 & 0.777 \\
\hline 4 & 2.041 & 0.594 & 0.834 & 2.187 & 0.776 & 0.766 \\
\hline 5 & 2.125 & 0.598 & 0.810 & 2.236 & 0.776 & 0.759 \\
\hline 6 & 2.197 & 0.603 & 0.791 & 2.274 & 0.777 & 0.753 \\
\hline 7 & 2.262 & 0.608 & 0.776 & 2.307 & 0.778 & 0.749 \\
\hline 8 & 2.308 & 0.612 & 0.766 & 2.332 & 0.779 & 0.745 \\
\hline 9 & 2.339 & 0.615 & 0.760 & 2.352 & 0.780 & 0.742 \\
\hline 10 & 2.369 & 0.617 & 0.754 & 2.373 & 0.781 & 0.739 \\
\hline 11 & 2.399 & 0.619 & 0.748 & 2.396 & 0.782 & 0.736 \\
\hline 12 & 2.428 & 0.620 & 0.743 & 2.420 & 0.783 & 0.733 \\
\hline 13 & 2.457 & 0.622 & 0.738 & 2.450 & 0.783 & 0.730 \\
\hline 14 & 2.608 & 0.631 & 0.713 & 2.584 & 0.788 & 0.713 \\
\hline 15 & 3.028 & 0.638 & 0.661 & 2.919 & 0.787 & 0.677 \\
\hline 16 & 3.359 & 0.595 & 0.627 & 3.230 & 0.771 & 0.648 \\
\hline 17 & 3.424 & 0.478 & 0.636 & 3.219 & 0.706 & 0.657 \\
\hline 18 & 3.573 & 0.360 & 0.638 & 3.318 & 0.590 & 0.663 \\
\hline 19 & 3.771 & 0.265 & 0.621 & 3.692 & 0.482 & 0.635 \\
\hline 20 & 4.116 & 0.192 & 0.585 & 4.248 & 0.407 & 0.587 \\
\hline
\end{tabular}

For Peralta tower a very poor correlation and a very high MAE were shown by the modeling from the WRF of the reality measured. Such behavior is very different from the one shown in the other towers, questioning the quality of the tower data from Peralta. Therefore, the analysis will continue with the towers Pampa and Piedras de Afilar, analyzing the level to be chosen. 
Regarding Pampa and Piedras de Afilar towers, the levels chosen were the ones with higher correlation coefficient between the tower and the modeled data, let say for Pampa tower the level selected was ETA level 15 for stable and ETA level 13 for unstable, while for Piedras de Afilar tower we proposed to use ETA level 15 for stable and ETA level 14 for unstable.

\subsection{Serie adjustment}

Once chosen the levels, an adjustment of the model output had to be considered, as the selected levels shown too high MAEs although having high correlations. Such adjustment objective was to generate the most accurate modeling of the reality measured in the towers.

After comparing different methodologies, the considered was a proportional one as result of the following two stages:

- First, the WRF serie was divided into two different series, one of stable thermodynamic state, and other of unstable thermodynamic state. Once such division was done, each serie was adjusted proportionally by a linear regression performed with the tower data available, obtaining the parameter $b$ and then both serial were put back together.

- Second, two series were generated, one with the monthly maximums of the measured serial, and another with the monthly maximums of the already adjusted data. The calculation of $\mathrm{b}$ as a proportional adjustment factor was done by linear regression between the series of maximum monthly values previously mentioned

The final adjustment done to the data simulated is given by the coefficient " $b$ " in Tab. 4 and defines as the result of multiplying b1times b2 for each tower and stability state.

Table 4: Proportional adjustment coefficient values

\begin{tabular}{ccccc}
\hline Tower & Thermodynamic stability & b1 & b2 & b \\
\hline \multirow{2}{*}{ Pampa } & Stable & 0.630 & \multirow{2}{*}{1.099} & 0.692 \\
& Unstable & 0.992 & & 1.090 \\
Piedras de & Stable & 0.661 & \multirow{2}{*}{1.068} & 0.706 \\
Afilar & Unstable & 0.713 & & 0.762 \\
\hline
\end{tabular}

The following plots show the comparison between cumulative frequency distribution obtained from the series achieved and the series measured for the period between years 2008 and 2015.
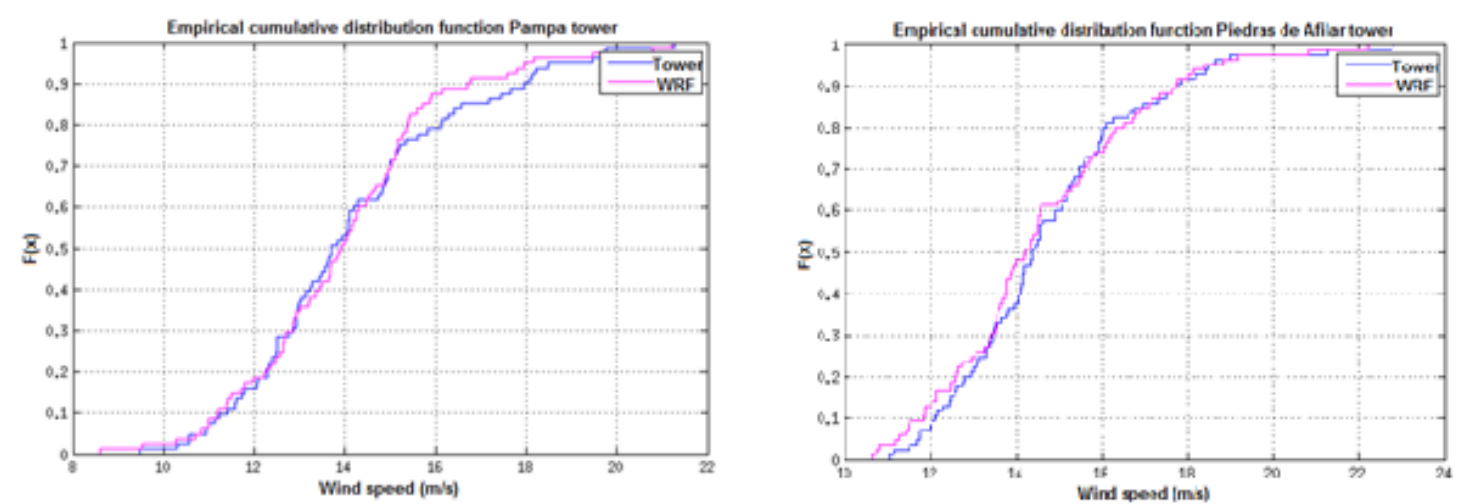

Figure 2: Empirical cumulative distribution function for Pampa and Piedras de Afilar towers

Figure 2 compares the behavior of the monthly maximum hourly mean wind speed frequency distribution measured in the tower with the ones produced by the adjusted model. Such plots, as the histograms shown in Fig. 3 show a good description of the reality. 

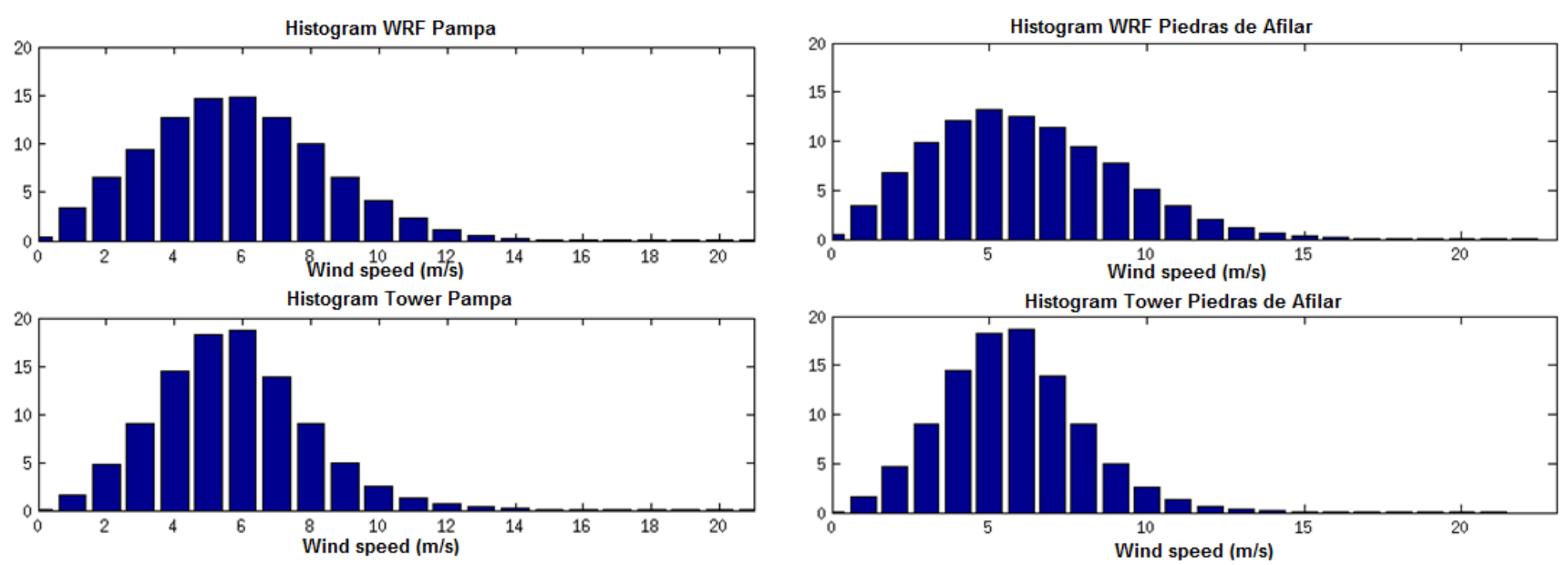

Figure 3: Histograms for Pampa and Piedras de Afilar towers

\subsection{Full period adjustment}

Once the proper adjustment for the WRF output series was calculated it was possible to extend it for the whole period of available CFSR data (1979 to 2015). The following figures show some statistics extracted from the resulting full period series, as some comparisons between such series and the available tower data.
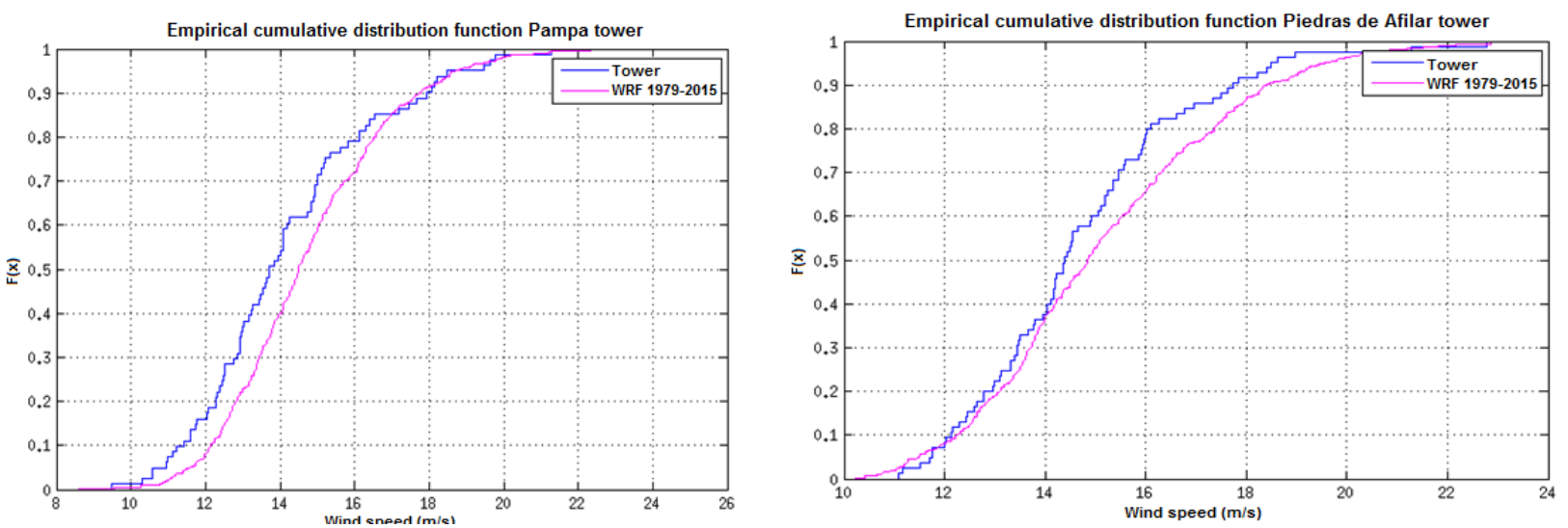

Figure 4: Empirical cumulative distribution function for Pampa and Piedras de Afilar towers

Figure 4 shows a comparison similar to the one shown in Figure 2, the difference is the period of modeled data which extends to the whole period of CFSR data availability (1979 up to present).

An interesting observation from the comparison of Figure 2 and Figure 4 is that the model plot moves to higher wind speeds, effect generated by the increase of monthly maximums values after the extension of the period modeled. Such increase in data available tends to generate more extreme wind speed values, generating some bigger monthly maximums and consequently moving the magenta plot slightly to the right. 

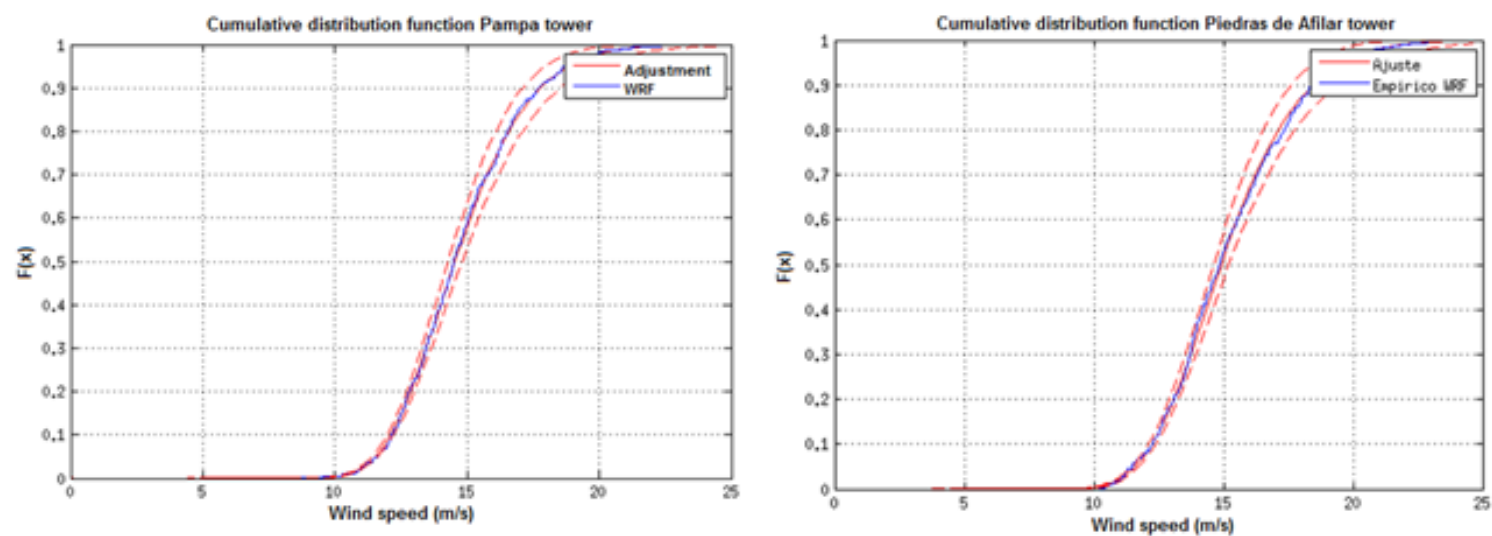

Figure 5 - Cumulative distribution function adjusted for Pampa and Piedras de Afilar tower

Figure 5 shows the Generalized Extreme Value (GEV) [9] cumulative distribution fit adjustment done to the empirical cumulative distribution function generated by the model for each tower. Once such plots where achieved, information about the return period for extreme mean hourly wind speed may be generated. Table 5 shows the wind speed, and the wind speed with $95 \%$ of trust for different return periods calculated from the distributions reached.

Table 5: Cumulative distribution function adjusted for Pampa and Piedras de Afilar tower

\begin{tabular}{|c|c|c|c|c|}
\hline \multirow{2}{*}{$\begin{array}{c}\text { Return Period } \\
\text { (years) }\end{array}$} & \multicolumn{2}{|c|}{ Pampa } & \multicolumn{2}{|c|}{ Piedras de Afilar } \\
\hline & $\mathbf{V}(\mathbf{m} / \mathbf{s})$ & V 95\% (m/s) & $\mathbf{V}(\mathbf{m} / \mathbf{s})$ & V 95\% (m/s) \\
\hline 5 & 20.3 & 21.9 & 21.3 & 23.1 \\
\hline 10 & 21.2 & 22.9 & 22.2 & 24.5 \\
\hline 15 & 21.6 & 23.5 & 22.7 & 25.3 \\
\hline 20 & 21.9 & 24 & 23 & 25.8 \\
\hline 25 & 22.2 & 24.3 & 23.3 & 26.2 \\
\hline 30 & 22.4 & 24.6 & 23.5 & 26.6 \\
\hline 35 & 22.5 & 24.8 & 23.7 & 26.9 \\
\hline 40 & 22.7 & 25 & 23.8 & 27.1 \\
\hline 45 & 22.8 & 25.2 & 24 & 27.3 \\
\hline 50 & 22.9 & 25.3 & 24.1 & 27.5 \\
\hline 55 & 23 & 25.5 & 24.2 & 27.7 \\
\hline 60 & 23.1 & 25.6 & 24.3 & 27.8 \\
\hline 65 & 23.1 & 25.7 & 24.4 & 28 \\
\hline 70 & 23.2 & 25.8 & 24.4 & 28.1 \\
\hline 75 & 23.3 & 25.9 & 24.5 & 28.2 \\
\hline 80 & 23.3 & 26 & 24.6 & 28.4 \\
\hline 85 & 23.4 & 26.1 & 24.6 & 28.5 \\
\hline 90 & 23.4 & 26.2 & 24.7 & 28.6 \\
\hline 95 & 23.5 & 26.3 & 24.8 & 28.7 \\
\hline 100 & 23.5 & 26.3 & 24.8 & 28.8 \\
\hline
\end{tabular}

\section{CONCLUSIONS}

A deep analysis between the data available and the numerical model WRF output was done. With the intention of getting a better response by the hourly mean monthly maximum wind speed modeled, an adjustment was considered. Such adjustment showed a good response to the reality measured in Pampa and Piedras de Afilar towers, allowing the generation of a trustworthy extention of the data available. The extention allowed the generation of more accurate cumulative distribution functions, generating important information of the return period for extreme values for each tower.

This methodology, not only offers interesting information for this particular cases of study, but also proves to be a usefull tool to quantify extreme wind speed in places where little 
measured information is available, allowing for example a territorial description of extreme values.

Regarding Peralta tower, further analysis must be carried out in order to guarantee the quality of the data measured and identify any particularity that may origin such behavior.

\section{REFERENCES}

1. Sanabria LA, Cechet RP. A statistical model of severe winds. 2007. Geoscience Australia.

2. Skamarock WC, Klemp JB Dudhia J, Gill DO, Barker DM, Wang W, Powers JG. A description of the advanced research WRF version 2 (No. NCAR/TN-468+ STR). 2005. National Center For Atmospheric Research Boulder Co Mesoscale and Microscale Meteorology Div.

3. Lucas EA. Análise do modelo numérico WRF-ARW em estimar a velocidade média do vento a distintas alturas nos primeiros 100 metros da camada limite planetária. 2015. Unipampa.

4. Gutierrez A., Cazes G, De Mello S. Operational wind energy forecast with power assimilation. In: 14 International Conference on Wind Engineering; 2015 Jun 21-26; Porto Alegre, RS.

5. Gutierrez A, Fovell R. Gust forecasting in Uruguay in support of wind energy. In: 14 International Conference on Wind Engineering; 2015 Jun 21-26; Porto Alegre, RS.

6. Gutierrez A, Cataldo J, Cazes G, De Mello S. Forecast cut out events in Emanuelle Cambilargiu 20 MW wind farm. In: 14 International Conference on Wind Engineering; 2015 Jun 21-26; Porto Alegre, RS.

7. Saha S, et al. NCEP Climate Forecast System Reanalysis (CFSR) Selected Hourly Time-Series Products, January 1979 to December 2010. 2010. Research Data Archive at the National Center for Atmospheric Research, Computational and Information Systems Laboratory, doi:10.5065/D6513W89.

8. Stull RB. An introduction to boundary layer meteorology. Springer Netherlands; 1988.670 p. doi: 10.1007/978-94-009-3027-8

9. Jenkinson AF. The frequency distribution of the annual maximum (or minimum) of meteorological elements. Q.J.R. Meteorol Soc. 1955;81:158-171, doi: 10.1002/qj.49708134804 